CASE REPORT PROF-2220

\title{
CAESAREAN SCAR PREGNANCY;
}

\section{A RARE CASE HISTORY}

\section{Dr. Razia Sultana, Dr. Saif-ul-Islam, Dr. Nurjahan.}

ABSTRACT......Caesarean Scar pregnancy (CSP) is a rare form of Ectopic pregnancy where the gestation sac is surrounded by myometrium and the fibrous tissue of the scar from the previous caesarean section. It is often misdiagnosed as Molar pregnancy or Inevitable Abortion and can be associated with massive hemorrhage and pervaginal bleeding leading to uterine rupture. Here we reported a case of Caesarean scar pregnancy who presented with history of cesarean section and pervaginal bleeding. Dilatation and curettage was planned but during the operative procedure there was profuse hemorrhage leading to hypovolumic shock which was managed by Blood and venesection then emergency laparotomy followed by Total Abdominal Hysterectomy done as life saving procedure, postoperative period was uneventful and the patient was discharged on $10^{\text {th }}$ postoperative day. Diagnosis is important as caesarean scar pregnancy is associated with life threatening complications such as uterine rupture, massive hemorrhage and the need for Hysterectomy with subsequent loss of fertility.

Key words: Caesarean scar Pregnancy (CSP), Ectopic pregnancy, Total Abdominal Hysterectomy (TAH), Transvaginal ultrasound, Colour Doppler, Uterine artery Embolisation. (UAE), Methotrexate (MTX).

Article Citation

Sultana R, Islam SU, Nurjahan. Caesarean scar pregnancy; a rare case history. Professional Med J 2013;20(5): 849-851.

\section{INTRODUCTION}

Caesarean scar pregnancy is a rare form of ectopic pregnancy where the gestation sac is surrounded by myometrium and fibrous tissue of scar from the previous caesarean section. The Endometrial cavity and fallopian tube is separated from the gestational sac. The CSP is a dangerous disease, as the trophoblastic invasion in the myometrium may lead to uterine rupture and profuse bleeding as the pregnancy advances ${ }^{1}$. Pregnancy within a caesarean fibrous tissue scar was first reported by Lansen and Solomon in $1978^{2}$. It may constitute a life threatening condition because of its high risk for massive vaginal bleeding and uterine rupture ${ }^{3,4}$. In the last decade, it has been encountered more frequently worldwide. The increased number of cases may reflect the greatly increased incidence of caesarean deliveres and the adoption of Transvaginal ultrasound or Colour Doppler imaging in recent years ${ }^{5,6}$. Cesarean scar pregnancy is diagnosed on patients having amenorrhea and a history of prior caesarean section. Diagnosis is based on sonographic and Doppler flow findings: (a). an empty uterus and cervical canal; (b). The gestational sac is located in the anterior part of the isthmus of the uterus with a diminished myometrial layer between the bladder and sac, (c). A discontinuity in the anterior wall of the uterus ${ }^{7}$. Most patients diagnosed with caesarean scar pregnancy are managed using one of the following Primary treatments: Dilatation and curettage (DEC), systemic Methotraxate as well as locally and Uterine Artery Embolisation (UAE) and conservative surgical treatment. Excision of the gestational sac followed by repair of the caesarean scar defect using either Laparotomy or Laparoscopy, has emerged a conservative therapy ${ }^{8}$, however the operation still carries a significant risk of uncontrolled hemorrhage, resulting in Hysterectomy and loss of reproductive function in some patients ${ }^{9}$.

\section{CASE HISTORY}

Mrs. X a young lady of 25 year old, mother of one child with history of caesarean section presented with history of amenorrhea for about 8 weeks, with mild pervaginal bleeding for two months. She was diagnosed initially as a case of incomplete abortion. She underwent Ultrasound of pelvic organ giving the differential diagnosis of Molar pregnancy, mass in the cervix and incomplete abortion. She was admitted in 
hospital for evacuation and curettage. During the procedure she develops severe pervaginal bleeding leading to Hypovolumic shock. Venesection was done So decision was taken for emergency Hysterectomy. After transfusion of 5 units of blood she underwent Total Abdominal hysterectomy. On laparotomy, small amount of blood was found in the peritoneal cavity. There was a longitudinal rupture on the lower part of body of the uterus and moderate amount of clotted blood was present in the uterine cavity. Urinary bladder was intact. Vaginal vault sutured. Postoperative period was uneventful. On $8^{\text {th }}$ postoperative day patient was discharged.

\section{DISCUSSION}

Caesarean scar pregnancy (CSP) is a rare form of Ectopic pregnancy, and is estimated to constitute approximately $1 \%$ of ectopic gestations ${ }^{10}$. The diagnosis is important as CSP is associated with life threatening complications such as uterine rupture, massive hemorrhage and the need for Hysterectomy with subsequent loss of fertility ${ }^{11-13}$. Although the exact mechanism of CSP is not known, it is believed that a highly possible predisposing factor for CSP is a micro tubular tract between the caesarean section scar and the endometrial canal. This tract is developed from the trauma of uterine surgery ${ }^{14}$. Thus conservative medical treatment, curettage and Hysteroscopy that leave the uterine defect unrepaired may potentially cause the recurrence of $\mathrm{CSP}^{15}$. Therefore Transvaginal surgery for caesarean scar pregnancy appears to be effective, safe and minimally invasive surgical treatment to remove ectopic pregnancy tissue and repair the underlying defect ${ }^{16-17}$. Ultrasonography is useful for diagnosing CSP. Because outcomes and treatment may differ, CSP must be distinguished from other types of abnormally implanted pregnancies. CSP is different from intrauterine pregnancy with placenta increta or percrata in that it is more aggressive, occurs in the first trimester and involves the complete embedding of the gestational sac in the myometrium. Valley et al18 reported a case confirmed by MRI which also demonstrated that no normal endometrium existed between gestational sac and the bladder wall. Strict imaging criteria must be used in performing the diagnosis-a empty uterus, empty cervical canal, development of the sac in the anterior part of the isthmic portion and an absence of healthy myometrium between the bladder wall and the gestational sac. A retrospective cohort study was done in University Hospital in China to determine the efficacy of Uterine Artery Embolisation (UAE) combined with local Methotrexate (MTX) for the treatment of Caesarean scar pregnancy between Jan 2003 and Dec 2008 and they concluded as UAE with local MTX is of benefit to women wishing to preserve fertility, and is suitable for use as a primary treatment of Caesarean scar Pregnancy ${ }^{19}$.

\section{CONCLUSION}

Caesarean scar pregnancy is one of the causes of maternal morbidity. Clinical presentation of CSP may mimic other disorders and result in diagnostic delay and mismanagement. Accurate diagnosis can be made by Sonographic and Doppler flow findings. Early diagnosis and use of multiple modalities can reduce morbidity in cases of ectopic pregnancy at unusual location. Surgical treatment or combined systemic and intragestational methotrexate were both successful in the management of Caesarean scar pregnancy. Because subsequent pregnancies may be complicated by uterine rupture, the uterine scar should be evaluated before as well as during these pregnancies.

\section{Copyright@ 25 Mar, 2013.}

\section{REFERENCES}

1. Fylstra DL Ectopic pregnancy within a Caesarean scar: a review, Obstet Gynecol surv 2002; 57: 537-43.

2. Larsen JV, Solomon MH. Pregnancy in a uterine scar sacculus- an unusual case of post abortal haemorrhage. S Afr Med J 1978; 53:142-3.

3. Rotas MA, Habermans Levgar M. Caesarean scar 
ectopic Pregnancies: Etiology, Diagnosis and Management. Obstet Gynecol 2006; 107: 1373-81.

4. Maymon R, Halperin R, Mendlovic S, Schneider D, Vaknin Z, Herman A, et al. Ectopic pregnancies in caesarean section scar: the $\mathbf{8}$ year experience of one medical center. Hum Reprod 2004; 19: 278-84.

5. Bregar AT, Cerar VM, Slaver ZZ, Verdenik I. Indications for caesarean deliveries between 1955 and 2005. Weinkin Wochenschr 2008: 120: 161-5.

6. Eskew PN Jr. Sayweli RM. Zollinger TW, ERner BK, Oser Th, Trends in the frequency of caesarean delivery. A 21 year experience, 1970-1990,J Reprod Med 1994; $39 ; 809-17$.

7. Jurkovic D, Hillaby K, Woelfer B, Lawrence A S, Salin R, ElsonC J, First trimester diagnosis and management of pregnancies implanted into the Lower Uterine Segment. Caesarean section scar. Ultrasound Obstet Gynecol 2003;21;220-7.

8. Graesslin 0, Fredenc Dedecker Jr, Christian Quereux, Rene Gabriel, Conservative treatment of ectopic pregnancy in a caesarean scar, Obstetcol Gynecol 2005; 105: 869-71.

9. Vial $Y$, Petgnat $P$, Hohlfield $P$, Pregnancy in a caesarean scar. Ultrsound Obstet Gynecol 2000; 16: 592-3.

10. Jiao L-Z Zhao J, Wan XR, Liu XY, Feng F_Z, Ren T, et al. Diagnosis and treatment of caesarean scar pregnancy. Chin Med Sci J 2008, 23: 10-5.

11. Herman A, Weinraub A, Avrecho, MaymonR, Ron El, Bukov sky Y. Follow up and outcome of isthmic pregnancy located in a previous caesarean section scar. Br. J Obstet Gynecol 1995; 102: 839-4.

12. Jurkovic D, Hillaby K, Woelfer B lawrence A, Saim R, Elson CJ, First trimester diagnosis and management of pregnancies implanted into the lower uterine segment Caesarean section scar. Ultrasound Obstet Gynecol 2003;21:220-7.

13. Maymon R, Halperin R, Mendloves, Schneider D,Vaknin Z. Herman A et al. Ectopic pregnancies in Caesarean section scars : the 8 year experience of one medical center. Hum Reprod 2004; 19: 278-84.

14. Fylstra DL, Ectopic pregnancy within a caesarean scar: a review. Obstet Gynecol surv 2002; 57: 537-42.

15. Haswgawa J, Ichizuka K, Matsuoka R, Otsukik, Sekizawa A, Okait. Limitations of conservative treatment for repeat caesarean scar pregnancy. Ultrasound Obstet Gynecol 2005; 25:310-1.

16. Wang Y, Sut, Chen H. Operative laparoscopy copy for un-ruptured ectopic pregnancy in a Caesarean scae. BJOG 2006; 113; 1035-8.

17. Wang $\mathrm{C}-\mathrm{J}$, Chao A-S, Yeoun L-T, Wang $\mathrm{C}-\mathrm{W}$, Soong Y-K, Leec_L. Endoscopic management of caesarean scar pregnancy. Fertil Steril. 2006; 85: 49, el-4.

18. Valley MT, Pierce JG, Dieniel TB et al. Caesarean scar pregnancy: Imaging with conservative surgery. Obstet Gynecol 1998; 9: 838-840.

19. X-Y Yang, H Yu, K Mli, Y-Y Chu, A Zheng. Uterine artery embolisation combined with local Methotrexate for treatment of caesarean scar Pregnancy, I J Obstet and Gynecol (BJOG). July 2010; 117: 990-996.

\section{AUTHOR(S):}

1. DR. RAZIA SULTANA

DGO, FCPS

Consultant Gyn. Obs.

2. DR. SAIF-UL-ISLAM

$\mathrm{DA}$

Assistant Professor, KMCH.

3. DR. NURJAHAN

MBBS

MO IBHK.
Correspondence Address:

Dr. Razia Sultana

Consultant Gynae

47 Khan Jahan Ali road, Shanti Dham More, Islami Bank Hospital Khulna. razia042@gmail.com 